\title{
Solid waste management transition in Selangor: issues and challenges
}

\begin{abstract}
Solid waste management in Malaysia has been facing many changes since a few decades ago. In September 1995, the Government decided to privatize the management of solid waste and in 2007 the Cabinet decided that the interim privatization is to cease for full privatization. With the Local Authorities (LAs) losing their authority, this privatization and enforcement of Act 672 has raised some dispute between the Federal Government and State Government in Selangor. Due to the conflict, Selangor has been exempted from the enforcement of the Act 672 and later terminate Alam Flora as their contractor. Therefore, the responsibility of managing the solid waste in each area will be under LAs and being monitored by the State Government. Based on the interview with several LAs officers in Selangor, this transition has positive and negative impacts to them. The termination of Alam Flora as their waste contractor can save a lot of money as they are managing the solid waste on their own. The LAs in Selangor is also directly involves with the process thus know the real situation of their solid waste scenario in their jurisdiction. Besides that, with the rotation system of hiring contractor in each LA, solid waste management can be improved. However, the LAs need to come out with their own plan for environmental program as Federal Government is not responsible for their solid waste management. Termination of Alam Flora has also increased workload for the LAs. Adaptation of new contractor has also caused time consuming and delay in solid waste disposal. This paper will discuss more on how this transition process gives impact to the LAs in Selangor.
\end{abstract}

Keyword: SWM; LAs; Federal government; Transition; Issues; Challenges 